\title{
Female and male orbit asymmetry: Digital analysis
}

\author{
Tomasz Lepich, A-D, F, Józefa Dąbek 2, B, C, E, Małgorzata Witkowska ${ }^{3, D, F}$, Edyta Jura-Szołtys ${ }^{4,}$ E, Grzegorz Bajor ${ }^{1, E}$ \\ ${ }^{1}$ Department of Human Anatomy, Medical University of Silesia, Katowice, Poland \\ ${ }^{2}$ Cardiology Department, Medical University of Silesia, Katowice, Poland \\ ${ }^{3}$ ENT Department, Medical University of Silesia, Katowice, Poland \\ ${ }^{4}$ Department of Internal Medicine, Allergology and Clinical Immunology School of Medicine \\ with the Division of Dentistry in Zabrze, Medical University of Silesia, Katowice, Poland \\ A - research concept and design; B - collection and/or assembly of data; C - data analysis and interpretation; \\ $D$ - writing the article; $E$ - critical revision of the article; $F$ - final approval of article
}

\section{Address for correspondence}

Tomasz Lepich

E-mail: lepich@sum.edu.pl

Funding sources

none declared

Conflict of interest

none declared

Received on November 27, 2014

Revised on April 22, 2015

Accepted on July 10, 2015

\begin{abstract}
Background. Standard anthropometric methods applied to measurements of the skull differentials are laden with mistakes stemming from the way the measuring devices are built and from a lack of experience on the part of the researchers. To increase objectivity, digital imaging measurements via computer systems were introduced.
\end{abstract}

Objectives. The aim of this research was to assess the asymmetry of the male and female orbit with the application of the new graphic methods: raster graphics and vector graphics.

Material and methods. The examination was conducted on 184 well-preserved skulls. The photos were taken by a digital camera with high definition. Orbit asymmetry was examined by determining the distance between the centers of gravity of both orbits and the frontal median line $\mathrm{d} 1$ and $\mathrm{d} 2$. Then angles $\mathrm{a}$ and $\beta$ were appointed. They are defined as angles between the line that runs through craniometrical points $\mathrm{mf}$ and ek on the right side (angle a) and on the left side (angle $\beta$ ), and the frontal median line at their crossing point. Distances $r 2$ and $r 1$, which are allocated points between the frontal median lines (LPP), were also set.

Results. Angles $a$ and $\beta$ were also analyzed while comparing the skulls of both genders. Statistically significant differences were only observed in male skulls. However, differences for both genders were noted in parameters $\mathrm{d} 1$ and d2. No statistically significant differences were discovered between men and women for parameters $r 1$ and $r 2$. The groups of women and men were merged, being treated as a population; which resulted in the conclusion that there are no statistically significant differences between these parameters.

Conclusions. The skull's asymmetry connected to gender and the asymmetry of the right and left sides of examined craniums can be used in criminal examinations as well as in facial reconstructive surgeries.

Key words: orbit, anthropometric methods, asymmetry

DOI

10.17219/acem/58783

\section{Copyright}

Copyright by Author(s)

This is an article distributed under the terms of the

Creative Commons Attribution Non-Commercial License

(http://creativecommons.org/licenses/by-nc-nd/4.0/) 
All vertebrates, including humans, are bilaterally symmetrical. The medial sagittal plane divides the human body into two symmetrical halves; the right and left (antimeres). In the early stages of ontogenesis, along with symmetrical differentiation, asymmetry gradually developed. Therefore, despite the general rules of symmetry, one may note the typical asymmetry of the human body. Asymmetry should be a topic of further studies because, as its intensity varies, some systematic traits prevail. ${ }^{1}$

Standard anthropometric methods applied to measurements of the skull differentials are laden with mistakes stemming from the way the measuring devices are built and the lack of experience of researchers. To increase objectivity, digital imaging measurements via computer systems have been introduced. A digital image analysis of the upper craniofacial massif (UMC) combines several computer graphic techniques, and has been acknowledged as a more accurate and reliable measurement method. ${ }^{2}$ A decision was made to develop a software program based on the two new methods of raster graphics and vector graphics. These methods would enable researchers to perform more accurate and repeatable measurements of UMC size and shape with emphasis on the quality and quantity of the orbits.

The purpose of conducting this research was to assess the asymmetry of the male and female orbit with the application of the new graphic methods: raster graphics and vector graphics.

\section{Material and methods}

The examination was conducted on 184 well-preserved skulls from the Middle Ages (10 $10^{\text {th }}$ to $13^{\text {th }}$ cent.) found at archeological digs in Kije and Złota Pińczowska, Poland, and made available by the Historical Anthropology Department of the Archeology Institute at the University of Warsaw. The above-mentioned archeological dig was described in a monograph by $\mathrm{M}$. Zoll-Adamkowa. ${ }^{3}$ Only mature and adult skulls preserved as calvaria, or whole skulls without the mandible, were examined. The skull age group was assessed based on their dentition and suture consolidation, which ranged from 20 to 55, with a 5-year margin of error. The skulls were divided by gender, male (105) and female (79). A steady location of the skull was achieved by placing it in a craniophore. This work involves the use of the Mollison's craniophore, with modifications.

In comparison with regular craniophores, the modified craniophore is built with 3 stands equipped at the top with screwed handles which the skulls are placed into. Two of the 3 screws hold the skull from the sides, and one screw is located in the sub-occipital region. The handles can be regulated to any given distance horizontally. To place the skull in the Frankfurt line, the craniophore is also equipped with a block containing a pointer that moves in the horizontal and vertical planes, allowing allocating the bottom verge of the orbit. The Frankfurt plane is allocated by horizontal lines running on the skull's lateral surface, from the bottom contour of both orbits to the upper contour of the acoustic external foramen. The Frankfurt line also runs through the bottom edge of the left orbit and the upper edge of the external acoustic meatus. In order to recurrently place all analyzed skulls in the frontal view (norma frontalis) the skulls were suspended with the upper verge of the metal spigot lodged in the external acoustic meatus, which was established as the upper edge of the orbit. On the skulls, the frontal view bregma point (b) was marked, which is necessary for further studies. Point $b$ is located where the coronal suture meets the sagittal suture. ${ }^{4}$ Frontal photos of the skulls were taken from a distance of $50 \mathrm{~cm}$. The frontal plane was parallel to the camera's objective.

The photos were taken by a digital camera with a high definition matrix of $2272 \times 1704$, and were saved in BMP format. Digital UMC images were analyzed using Digital Image Cranio-Analyzer (DICA) 2.0, which is an original program developed by the Department of Human Anatomy at the Medical University of Silesia. ${ }^{5}$ Orbit asymmetry was examined by determining the distance between the centers of gravity of both orbits and the frontal median line $\mathrm{d} 1$ and $\mathrm{d} 2$. Then angles $\alpha$ and $\beta$ were appointed. They are defined as angles between the line that runs through craniometric points $\mathrm{mf}$ and ek on the right side (angle $\alpha$ ) and on the left side (angle $\beta$ ), and the frontal median line at their crossing point. Distances $\mathrm{r} 2$ and $\mathrm{r} 1$, which are allocated points between the frontal median lines (LPP), were also set (Fig. 1).

\section{Statistical analysis}

1. All of the craniometric measurement values considered are given in $\mathrm{mm}$, the angles in degrees and surface area is expressed in square $\mathrm{mm}^{2}$. At the beginning of the statistical analysis, descriptive statistics were enumerated such as arithmetic averages and standard deviations for each attribute in the male and female skulls. The results in the tables are given in the form of arithmetic averages \pm SD.

2. To assess the differences between various groups in arithmetic averages, a t-Student test was used.

3. The Kolmogorov-Smirnov test was used to ensure the compatibility of empirical examined variable distributions, with normal distribution separated in groups of male and female skulls.

4. Variance's homogeneity was estimated by Levene's test. If the condition of variance's homogeneity was not met, the Cochran-Cox test was used. ${ }^{6}$ When the data did not demonstrate a normal distribution, the Mann-Whitney $U$ test was used.

5. The association between the examined features was checked by using the Pearson's Quotient Significance 


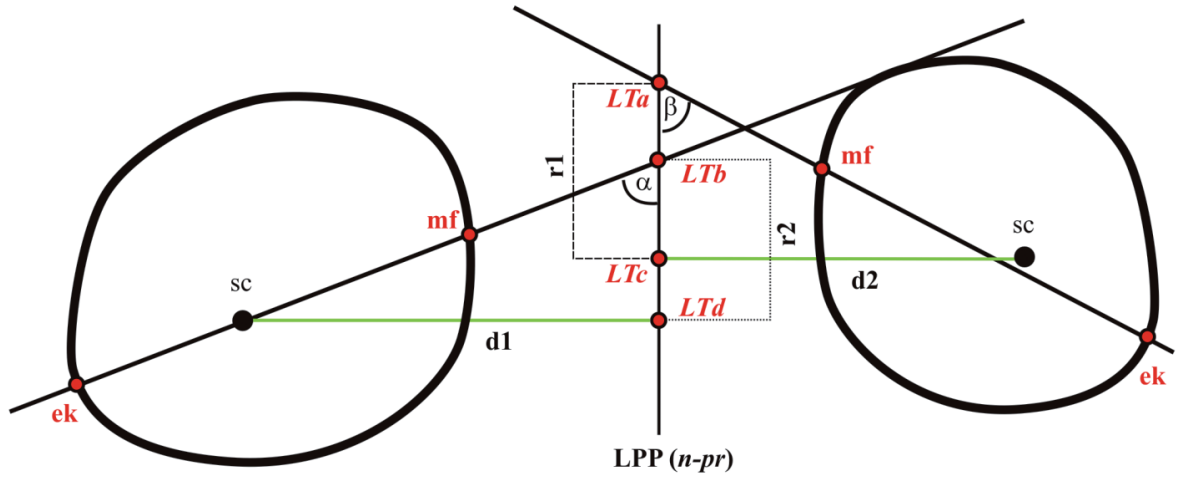

Fig. 1. Orbit's asymmetry measurement diagram

Correlation Test. ${ }^{7}$ Correlations were also presented by Terentyev's Pleiades. ${ }^{8}$

6. Descriptive statistics, parametric and non-parametric tests for differences in averages and correlation analysis were performed using the SAS Learning Edition 2.0 program (SAS) and package $\mathrm{R}$, and the analysis of the main components along with a graphic result depiction was performed using the CANOCO 4.5 trial version (CANOCO). Linear regression graphs were produced using STATISTICA 6.0 PL (StatSoft, Poland).

\section{Results}

\section{Orbit asymmetry in male and female skulls}

Angles $\alpha$ and $\beta$ were analyzed while comparing the skulls of both genders. Statistically significant differences were only observed in male skulls. Parameters d1, d2, r1, and $r 2$ were larger in male skulls. No differences between angle $\alpha$ and $\beta$ were noted. However, differences for both genders were noted in parameters $\mathrm{d} 1$ and $\mathrm{d} 2$. Since no statistically significant differences were discovered between men and women for parameters $\mathrm{r} 1$ and $\mathrm{r} 2$, the group of women and men were merged, treating it as a population. This resulted in the conclusion that there are no statistically significant differences between these parameters $(\mathrm{p}=1.0)$ (Table 1$)$

Orbit asymmetry was examined by measuring the distance from the orbit's center of gravity to the line running

Table 1. Comparison of parameters measurements associated with male and female skull asymmetry: $\sigma^{\prime \prime}-$ male skulls, $\mathrm{Q}-$ female skulls. Additional parameters include: $\mathrm{X}$ - arithmetic average, SD - standard deviation, $\mathrm{p}$ - importance level

\begin{tabular}{|c|c|c|c|c|}
\hline Parameters & Sex & \multicolumn{2}{|c|}{$\mathrm{X}$} & $\mathrm{p}$ \\
\hline angle $a\left[^{\circ}\right]$ vs. angle $\beta\left[^{\circ}\right]$ & $\begin{array}{l}0^{\prime} \\
\text { Q }\end{array}$ & $\begin{array}{l}80.15 \\
80.59\end{array}$ & $\begin{array}{l}78.93 \\
80.08\end{array}$ & $\begin{array}{l}0.047 \\
0.809^{*}\end{array}$ \\
\hline $\mathrm{d} 1$ [mm] vs. d2 [mm] & $\begin{array}{l}\sigma^{7} \\
\text { Q }\end{array}$ & $\begin{array}{l}31.63 \\
30.83\end{array}$ & $\begin{array}{l}30.45 \\
29.25\end{array}$ & $\begin{array}{l}0.001 \\
0.001\end{array}$ \\
\hline $\mathrm{r} 1[\mathrm{~mm}]$ vs. $r 2[\mathrm{~mm}]$ & $\begin{array}{l}0^{n} \\
\text { O }\end{array}$ & $\begin{array}{l}7.47 \\
6.59\end{array}$ & $\begin{array}{l}8.02 \\
7.10\end{array}$ & $\begin{array}{l}0.122^{*} \\
0.296^{*}\end{array}$ \\
\hline
\end{tabular}

through points $\mathrm{n}$ and $\mathrm{pr}$, the angles contained between the lines running through points $\mathrm{mk}$, ek, $\mathrm{n}$ and $\mathrm{pr}$, as well as the distance between the points that are adjacent to the skull's frontal median line that crosses with points $\mathrm{mf}$ and ek.

The analysis of male skull asymmetry demonstrated a positive, statistically-significant correlation $(r=0.76$, $\mathrm{p}<0.01$ ) between parameters $\mathrm{d} 2$ and $\mathrm{d} 1$. Identical patterns were demonstrated for the same parameters in the group of female skulls $(\mathrm{r}=0.77, \mathrm{p}<0.01)$.

The correlation between $r 1$ and angle $\alpha$ was negative in both female and male skulls. Pearson's quotient for this analysis equaled $-0.56, \mathrm{p}<0.01$ for females and -0.57 , $\mathrm{p}<0.01$ for males (Fig. 2). While analyzing $\mathrm{r} 2$ parameters with angle $\beta$, a negative correlation was found $(\mathrm{r}=-0.55$, $\mathrm{p}<0.01$ ) in the group of male skulls (Table 2, 3).

Comparing the skulls of both genders by Pleiades correlation has shown an additional correlation between variables angle $\beta$ and $\mathrm{d} 2$, as well as between parameters $\mathrm{r} 1$ and r2 (Fig. 3).

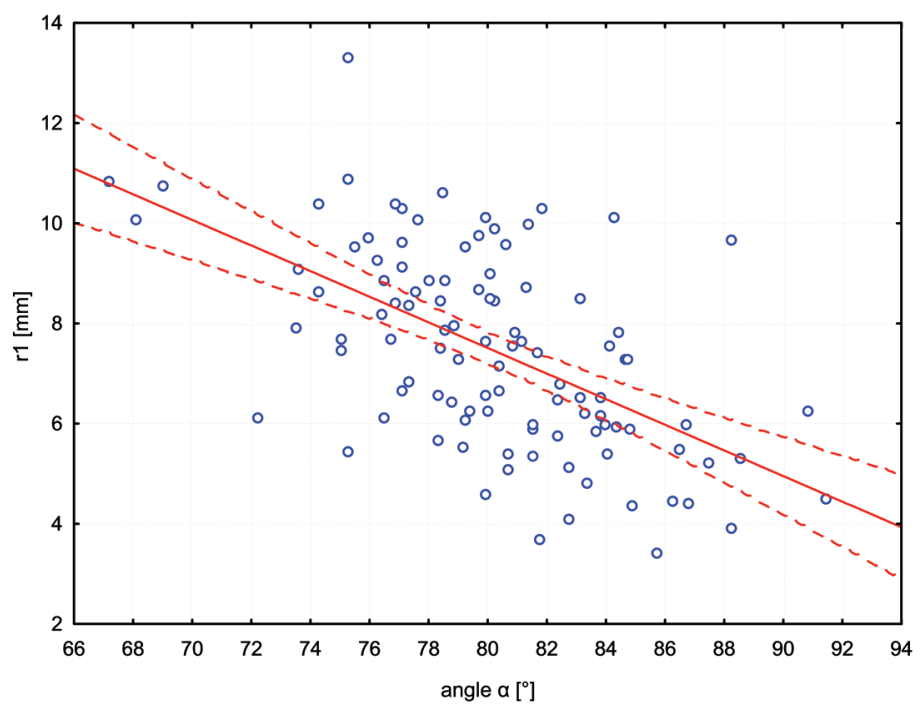

Fig. 2. Dispersion graph and regression curve for the angle Fontaine between a line running through points $\mathrm{mf}$ and ek of the right orbit and median line (angle $a$ ) and for the distance from point LTa to point LTC ( $r 1$ ) in male skulls $\left(r=-0.57, y=27.962-0.2556^{*} x\right), p<0.05$ 
Table 3. Parameter's correlation specifying orbit asymmetry in female skulls

\begin{tabular}{|c|c|c|c|c|c|c|}
\hline & Angle $a\left[^{\circ}\right]$ & Angle $\beta\left[^{\circ}\right]$ & $\mathrm{d} 1[\mathrm{~mm}]$ & $\mathrm{d} 2[\mathrm{~mm}]$ & $\mathrm{r} 1[\mathrm{~mm}]$ & $\mathrm{r} 2[\mathrm{~mm}]$ \\
\hline Angle a $\left[^{\circ}\right]$ & 1.00 & & & & & \\
\hline Angle $\beta\left[^{\circ}\right.$ ] & 0.37 & 1.00 & & & & \\
\hline $\mathrm{d} 1$ [mm] & 0.10 & 0.07 & 1.00 & & & \\
\hline $\mathrm{d} 2[\mathrm{~mm}]$ & 0.14 & 0.09 & 0.77 & 1.00 & & \\
\hline r1 [mm] & -0.53 & -0.30 & 0.04 & 0.01 & 1.00 & \\
\hline r2 [mm] & -0.02 & -0.32 & 0.13 & 0.16 & 0.28 & 1.00 \\
\hline
\end{tabular}

Table 2. Parameter's correlation specifying orbit asymmetry in male skulls

\begin{tabular}{|c|c|c|c|c|c|c|}
\hline & Angle a $\left[^{\circ}\right]$ & Angle $\beta\left[^{\circ}\right]$ & $\mathrm{d} 1[\mathrm{~mm}]$ & $\mathrm{d} 2[\mathrm{~mm}]$ & $\mathrm{r} 1[\mathrm{~mm}]$ & $\mathrm{r} 2[\mathrm{~mm}]$ \\
\hline Angle a $\left[^{\circ}\right]$ & 1.00 & & & & & \\
\hline Angle $\beta\left[^{\circ}\right.$ ] & 0.47 & 1.00 & & & & \\
\hline $\mathrm{d} 1$ [mm] & 0.04 & 0.15 & 1.00 & & & \\
\hline $\mathrm{d} 2$ [mm] & 0.06 & 0.21 & 0.76 & 1.00 & & \\
\hline $\mathrm{r} 1[\mathrm{~mm}]$ & -0.57 & -0.23 & 0.31 & 0.20 & 1.00 & \\
\hline $\mathrm{r} 2[\mathrm{~mm}]$ & -0.16 & -0.55 & 0.11 & 0.05 & 0.40 & 1.00 \\
\hline
\end{tabular}
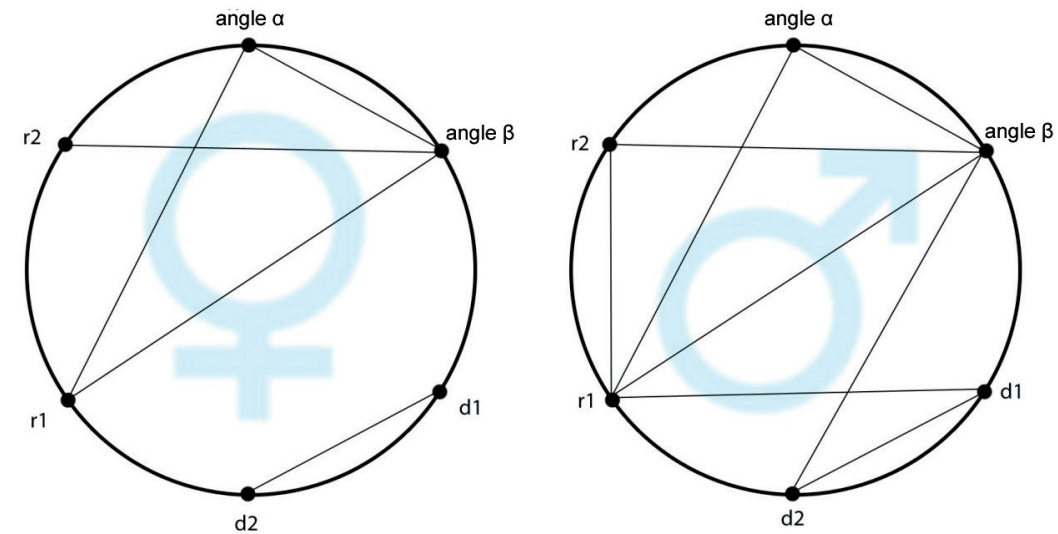

Fig. 3. Parameter's correlation Pleiades specifying orbit asymmetry in male and female skulls

\section{Discussion}

The issue of asymmetry in the human body has been a topic of interest in the field of science for a long time. The human body is built on a bilateral symmetry plan. Asymmetry refers to not only the external characteristics of the human body, which is visible in the mirror and of the structure of bones and muscles, and even the central nervous system. In a complicated structure such as the skull, perfect symmetry does not exist. Facial asymmetry is a proof of the fact that the face is expressive, more so on the left side. ${ }^{9}$ In Smith's thesis, face asymmetry was studied in a group of men and women. To this end, photographs of faces were digitally analyzed by the CANVAS program, which measures the surface of the face. A perpendicular line to halve the distance between the centers of the pupil line was set, thus defining the right and left side of the face; then both areas were measured. Highly significant statistical correlations between males and females were proven for both the right and left side of the face $(r=0.99)$. In the group consisting of females, the area of the right side of the face $\left(3.16 \mathrm{~cm}^{2}\right)$ was bigger than the left side $\left(2.93 \mathrm{~cm}^{2}\right){ }^{10}$ From the research we conducted, the width of the right side of the face in females (set by the distance between the nasion point and anthropometric zygomaxillare and frontomalare orbital points, and between subspinale and zygomaxillare points) was also greater. Similarly, the parameters describing the width of the right side of the face in males were also greater, contrarily to Smith's results.

Asymmetry of the face can be connected to asymmetry of the brain. Those affiliations result from neurological control of the right and left side of the face by two brain hemispheres. The left hemisphere controls the right side of the face, while the left side of the face is governed by the right hemisphere. On top of that, variations in activity in brain hemispheres can influence both sides of the face. Gender related differences are also visible from an early age, and can last for the lifespan of the individual. ${ }^{11}$ 
Spatial process hemispheres are responsible for the basic differences associated with gender, and are involved with verbal and visual cues. Hence the predominance of the right side of the face in females, which is controlled by the left hemisphere, in turn is associated with verbal processes. Face asymmetry also stems from the extent of how many muscles are in the face. The active side of the face is wider, longer and more muscular according to Smith. ${ }^{10}$ In Zaidel's research, people had to assess the attractiveness of a woman's face and researcher revealed that the right side is more attractive than the left one.

Face asymmetry analysis is performed mainly by using radiological imaging and CT scans which use stereophotogrammetric methods and 3-dimensional CTor bilateral comparison of craniometric points in reference to the frontal median line. Craniometric points on the skull in norma frontalis were identified by Parzianello and coauthors with an automatic method of their detection. ${ }^{13-17}$ They analyzed the distances between the orbits center of gravity and the cranium central point (centroid); which is located in the frontal median line. They also measured the angles formed between the face's frontal median line and the orbits centers' of gravity and their distance to the line.

The authors noticed a greater angle value and a greater distance on the left side. The techniques depicted by the aforementioned authors are different from the way of allocating the face's asymmetry performed by the author in their research, where the smallest distance between the center of gravity and the frontal median line was measured. The research showed that the distances from the centers of gravity in the male and female skull population varied, showing greater values on the right side. It has also been revealed that the angles between a line leading through points $\mathrm{mf}$ and ek of the right orbit and lines connecting points $\mathrm{n}$ and pr were similar in male and female skulls. In male skulls, differences between the right and left side were observed. All other parameters indicated statistically significant differences connected to gender.

Several types of asymmetry exist. Some kinds of skull asymmetry can be the result of trauma or a development disorder. This kind of asymmetry is not the topic of discussion in this dissertation. Asymmetries also stem from the laterality of the human body, mainly the skull's laterality. The term laterality, also known as the dominance of brain hemispheres, involves the preferential usage or overriding function of one body part. In 1858, Jackson suggested the term "dominant hemisphere". ${ }^{18}$ In terms of functionality, both hemispheres control basic body movements and sensations contralaterally. Such basic body movements and sensation administration resulted in the left hemisphere controlling the right side of the body, and the right hemisphere controlling the left side.

It has been proven that lateralization is a natural effect of the functional specialization of this organ. ${ }^{19,20}$ Functional asymmetry is a manifestation of the dominance of one of the brain hemispheres. The dominance mir- rors the development of the nervous system, from simply symmetrical to more complex; then finally a coordinated and specialized system of symmetry. One of the most important manifestations of the dominance of hemispheres is the so-called "hand preference" (handedness). As it is commonly known, most people use their right hand. According to Corballis, the degree to which a hemisphere is dominant is a functional property, and it intellectually separates humans from higher primates and other mammals. $^{21}$

Authors Dayi et al. propounded that certain functional features of the brain, such as handedness and cognition, may be linked to the skull's morphology (the skull's width on the right and left side). ${ }^{22}$ Some authors argue the size of the brain is connected to tooth development, and thus is a connection between the development of the skull and the brain's cognition and motor function. ${ }^{23}$ As an example of the connections between the skull's structure and the brain's functions, the authors used people with Downs Syndrome as an example. Patients with underdeveloped brain also have an underdeveloped skull, especially the maxilla.

In addition, Blaschke et al. argue that the relationship between brain and skull morphology is genetically determined, and they identified human homeobox gene, SHOT, which is involved in the development of the skull, brain, heart, limbs, and other additional structures. ${ }^{24}$ The authors, who demonstrated the link between the width of the skull and functional features of the brain, examined 24 men and 29 women from the ages of 19-22.

In the examined group, handedness was determined by Oldfield's questionnaire; which is used to assess laterality. Based on the results, men and women were classified into groups of dextral and sinistral. Perceptive-motoric integration was assessed using the PMT test (Peg Moving Task). The width of the skull was measured on cephalometric radiographs performed using the X-ray technique in the norma frontalis position, which is performed by measuring the distance between the zygion points in the orbitomeatal line. The width of the face on both the left and the right side, and the differences between the right and the left (R-L) sides of the skull were measured in relation to the median frontal line. Multidimensional analysis demonstrated that gender and handedness are important factors influencing the widths of both right and left sides of the face. Gender-handedness interaction was statistically irrelevant.

It has been proven that the skull's width on both sides was greater in men than in women, which is statistically significant. However, the width of the left side of the face, regardless of sex, was statistically greater in dextral than sinistral people. The face's R-L differences were significantly greater only in sinistral people. The face's symmetry in both genders has also been studied. $57.7 \%$ of women, in comparison to men, had bigger faces on the right side $(\mathrm{R}-\mathrm{L}>0)$ than on the left side $(38.55(\mathrm{R}-\mathrm{L}<0)$. 
$52.2 \%$ of men had wider faces on the left side than on the right (43.5\%). Still, $3.8 \%$ of woman and $4.3 \%$ of men had symmetrical faces $(\mathrm{R}-\mathrm{L}=0)$. It's been noted that there is a tendency in female skulls for the face's right side to be wider, whereas in men, the left side is wider.

A correlation was found between the differences in the width of the left and right side of the face, and the face's width in dextral and sinistral. No differences have been noted between the width of the face on the right and the $\mathrm{R}-\mathrm{L}$ difference. However, a correlation has been noted between the $\mathrm{R}-\mathrm{L}$ width's differences. In dextral women, a difference in $\mathrm{R}-\mathrm{L}$ width was noticed which correlated significantly only with the width of the left side. In dextral men, a correlation between the face's R-L difference and the width of the face's right side was established. Visual-motoric abilities were evaluated using the PMT test. The link between the left and right side of the face, and the $\mathrm{R}-\mathrm{L}$ width was examined.

In sinistral men, the left hand's abilities have been proven to increase with decreasing advantage of the left side of the face and increasing advantage of the right side. Additionally, it has been proven that a wider face on the right side correlates with L-R PMT in sinistral. In dextral, the right hand's abilities increased with the decreasing advantage of the left side of the face and with the increasing advantage of the right side. Greater facial width on the right side and usage of the right brain hemisphere in visual-motoric abilities are very important for both the faces asymmetry and handedness.

One of the asymmetry types is morphologic asymmetry. Morphologic asymmetry usually presents itself in domination of the left side of the cranium. Asymmetry in the cranial region can have a quantitative and qualitative aspect. In fetuses and newborns, cranial asymmetry is not prominent. Craniostenosis is a deformation in the symmetry of a child's skull. Craniostenosis occurs when the cranial sutures ossify before birth or during the first months of life. Accretion of even one of the sutures causes the brain to grow in a direction free of oppression, which in turn causes cranial and facial deformations. Some cases of craniostenosis are a result of genetic abnormalities.

The etiology of most craniostenosis remains unknown. However, the influence of earth's gravity on cranial form is known. The deformation in a skull can be caused by prolonged exposure to a gravitational acceleration vector. The results of gravity's effect can cause brachycephaly, or flattening of the postern part of the skull. The postern plagiocephaly proposed by Lee, et al. examined the skulls of children with plagiocephaly. Cranial asymmetry measurements were performed immediately after cranioplastic surgery. ${ }^{25}$ Five years after surgery, the asymmetry was evaluated through measurements of the fornix of the skull. The depth between the orbital and tragus points of the skull, as well as the base of the cranium, was evaluated. What was noted were the parameters describing the base of the skull and the progression of asymmetry.
The progression of plagiocephaly can be evaluated by examining cranial asymmetry, which is performed by calculating the cranial indicator as width divided by length of the skull expressed in percentage. ${ }^{26,27}$

Usually the measurement of cranial width is performed by measuring the distance between the euryon points. The width of the cranium is the distance between the glabella point and the opisthocranion point. Euryon points are located most laterally on the cranium, mostly in the bottom occipital bone region in median plane. The author's research included hanging the craniums on the craniostat. Measuring the cranial width between zygion points was impossible, however the distance between zma points (zma-zma) was measured.

The manifestations of cranial morphological asymmetry escalate with age due to cranial development. ${ }^{28,29}$ Some authors argue that age has no influence on asymmetry of the cranium. ${ }^{30}$ During the ontogenetic development of the skull, it is noted upon birth that the height of the viscerocranium equals $60 \%$ of the cranial height in a newborn and $40 \%$ in an adult. It can be concluded that in an adult, the viscerocranium has a capacity greater by 8 times. Morphological asymmetry in the cranial region can cover, among others, maxillary sinuses, frontal sinuses and asymmetric nasal septum. ${ }^{31-33}$ Authors Wysocki et al. came to the conclusion that, in humans, the ratio of the venous foramen's surface to the capacity of the cranial cavity is significantly lower than in animals. ${ }^{34}$ It has been noted that asymmetry characterizes the size of the venous foramen for the cardiac veins, and it occurs more often in humans than in animals.

The size of this asymmetry in the case of the venous foramen in humans amounts to roughly 1.6. In about $8 \%$ of people, the disproportion between the surface of the right and left jugular foramen exceeds 200\%, and it constitutes a contraindication to the procedure of ligating the jugular vein on this side. In the case of the right side's dominance, there is a connection between the size of the cranial cavity and the size of the venous foramen. The larger the cranium size, the smaller the asymmetric value is. When the left side is dominant, the correlation is positive - the bigger the capacity of the cranium, the greater the size of the venous foramen. The research performed constitutes proof for systematic asymmetry in humans. The differences in dimensions from the left and right sides of the viscerocranium are intensified proportionally to the increase in dominance of the left brain hemisphere.

In proportion to the dominance of the left hemisphere of the brain, there are differences in the dimensions of the left and right hemispheres. Proportionally to this, the left side of the face has also enlarged its width on to the right side, which is usually narrower but slightly longer. Some authors provide examples to prove the dominance of the right side; and some favor the left side. ${ }^{35-37}$ Also, the results of this research show that a part of the examined 
skulls showed the dominance of the right side and some of the left side. The values of the distance between subspinal and frontomalar orbital points were the key factors in this. The distance between nasion and zygomaxillare points were congruous with the data from references and they attest to the difficulties in completely unequivocal assessment of the dominance of one of the sides. This is also confirmed by Woo's research. ${ }^{38}$

Functional asymmetry is connected to the dominance of one of the brain hemispheres (the dominance of the left hemisphere is preponderant). It manifests in functional attributes. A conjugation between morphological and functional asymmetry exists. It could be thought that from brain lateralization, facial lateralization should stem. Functional brain development influences physiological functions of the face. The face takes part in inter-human communication. Additionally, the viscerocranium takes part in the process of articulating sounds, and in humans it constitutes the basis of communication, such as speech. A lateralized brain is handled by the eyes. In the optic tract, asymmetry is also present. The optic nerve, which is regarded as the brain's inset, transmits impulses through the optic chiasm to the occipital lobe of the brain. In this case, sensory asymmetry can be observed as it relies on the differences in sensitivity between the right and left eye. Usually an advantage of the right eye (RVF - right visual field) and the right ear (REA - right ear advantage) is found.

A hypothesis has been stated that the advantage of one of the sides regarding the eyes arises during the development of the viscerocranium during the fetal stage, during which the advantage of the auricular organ is connected to the fetus's position in the final trimester of the pregnancy. The advantage of the right ear can cause the advantage of the left brain hemisphere in as far as speech and functions of language.

Hemisphere domination techniques are so-called lateralization techniques, used before functional magnetic resonance imaging or PET (positron emission tomography). These were constructed relying on neuropsychological examinations. The patient identified words heard in the right and left ear. In 1963, Kimura noticed that patients with damage to the left temporal lobe achieved worse results in comparison to patients with damage in the right lobe. ${ }^{39}$ Using an instrument called a tachistoscope, visual impulses in spaces of milliseconds were presented to the patient. Because the optic tract is crossed, the information is transmitted to the opposite brain hemisphere than the eye which received the information. By using this technique it has been discovered that the words which were presented for a short period of time in the right visual field and were processed by the left hemisphere are better identified than the words presented to the left visual field and processed by the right hemisphere. ${ }^{41}$ This technique is often used in examining patients with splitbrain. There is, however, no easy way to divide people into groups of ambidextrous, dextral and sinistral. Classifying handedness to this day causes a lot of problems. The preference of one hand influences brain hemisphere asymmetry, most likely because in dextral and sinistral brains the speech centers are organized differently. Aside from handedness, preferences in other structures, such as the eyes, can be distinguished. Sometimes heterogeneous dominance, which presents with, for example, dominance of the left eye and the right hand, or a different combination, occurs. According to Luria, the higher the activity is organized, the more asymmetrical it becomes. ${ }^{41}$

Because humans are thinking beings, they have the ability to communicate through speech, and a clear dominance of brain hemispheres can be observed. In consequence, the morphological asymmetry of the face can be quantified and observed.

\section{Conclusion}

Based on the research performed, it can be said that cranial asymmetry is present in both genders, however it is more prominent in males. Lateralization is also present. In addition, asymmetry has been proven in both female and male skulls, stemming from higher values of the examined parameters of the right orbit in absolute numbers as well as normalized numbers. The skull's asymmetry connected to gender and the asymmetry of the right and left side of the examined craniums can be used in criminal examinations as well as in facial reconstructive surgeries.

\section{References}

1. Wysocki J. Anatomia otworów żylnych czaszki u człowieka i wybranych gatunków zwierząt. Rozprawa habilitacyjna, Akademia Medyczna w Warszawie, Warszawa 2002.

2. Lepich T, Dąbek J, Stompel D, Gielecki JS. Analysis of the upper massif of the craniofacial with the radial method - practical use. Arch Med Sci. 2011;7:870-876.

3. Zoll-Adamikowa M. Wczesnośredniowieczne cmentarzyska szkieletowe Małopolski cz. I. Zakład Narodowy im. Ossolińskich, Wydawnictwo Polskiej Akademii Nauk. Wrocław-Warszawa-Kraków, 1996, 61-62.

4. El-Hayeck E, Bou Assi S, Bou-Serhal J. Clinical study of orientation and reference planes in cephalometry. Orthod Fr. 2005;76:217-227.

5. Gielecki J, Gajda G, Gasiński MJ. Radial method for analysis of human orbit's symmetry. Komputerowe wspomaganie badań naukowych. IX KK KOWBAN 2002, 141-144.

6. Dobosz M. Wspomagana komputerowo statystyczna analiza wyników badań. Akademicka Oficyna Wydawnictwa Exit, Warszawa 2004.

7. Malinowski A, Wolański N. Metody badań w biologii człowieka. Wybór metod antropologicznych. Warszawa PWN; 1998:92-93.

8. Terentiev VP. The method of correlation Pleiades. Vestnik Leningrad Univ, 1959, 9.

9. Mercier JM, Perrin JP, Longis J, Arzul L, Corre P. Facial asymmetries and their skeletal component. Rev Stomatol Chir Maxillofac Chir Oral. 2014;115:219-228.

10. Smith W. Hemispheric and facial asymmetry: Gender differences. Laterality. 2000;5:251-258.

11. Cheong YW, Lo LJ. Facial asymmetry: Etiology, evaluation, and management. Chang Gung Med J. 2011;34:341-351. 
12. Zaidel DW, Fitzgerald P. Sex of the face in Western art: Left and right in portraits. Empirical Studies of the Arts. 1994;12:9-18.

13. Mclntyre GT, Mossey PA. Asymmetry of the parental craniofacial skeleton in orofacial clefting. Journal of Orthod. 2002;299-305.

14. Kozłowski T, Cybulska M, Błaszczyk B, Krajewska M, Jeśman C. Skull deformations in craniosynostosis and endocrine disorders: Morphological and tomographic analysis of the skull from the crypt of the Silesian Piasts in Brzeg (16 $16^{\text {th }}-17^{\text {th }}$ century), Poland. Homo. 2014;65:400-422.

15. Baek C, Paeng JY, Lee JS, Hong J. Morphologic evaluation and classification of facial asymmetry using 3-dimensional computed tomography. J Oral Maxillofac Surg. 2012;70:1161-1169.

16. Majid Z, Chong A, Setan H, Ahmad A. Three dimensional craniofacial anthropometry using stereophotogrammetry: Validation of the technique. In: International Symposium \& Exhibition on Geoinformation 2005 Geospatial Solutions for Managing the Borderless World, 27-29.09.2005, Pulau Pinang.

17. Parzianello LC, Da Silveira MM, Furuie SS, Palhares FAB. Automatic detection of the craniometric points for craniofacial identification. Anais do IX SIBGRAPI. 1996;189-196.

18. Jackson JH, J. Taylor. Selected writings of John Hughlings. N.Y Basic Book, 1958.

19. LeMay M. Functional and anatomical asymmetries of the human brain. European Journal of Neurology. 1999;6:79-85.

20. Hugdahl K. Symmetry and asymmetry in the human brain. European Review. 2005;13:119-133.

21. Corballis M. The Lopsided Ape. NY Oxford University Press, 1991.

22. Dayi E, Okuyan M. Predictability of hand skill and cognitive abilities from craniofacial width and left-handed men and women relation of skeletal structure to cerebral function. Intern J Neuroscience. 2002;112:383-412.

23. Godfrey LR, Samonds KE, Junkers WL, Sutherland MR. Teeth, brains and primate life histories. American J of Physic Anthrop. 2001;114:192-214.

24. Blaschke RJ, Monaghan AP, Schiller S et al. SHOT, a SHOT-related homeobox gene, is implicated in craniofacial, brain, heart and limb development. Proceedings of National Academy of Sciences. 1998:95:2406-2411.
25. Lee R, English J, Duke J, Teichgraeber J. Gravitational and Space Biology. 2006;19:137-138.

26. Zonenshayn M, Kronberg E, Soiweidane MM. Cranial index of symmetry: An objective semiautomated measure of plagiocephaly. J Neurosurg. 2004;100:537-540.

27. Farkas LG, Munro IR. Anthropometric facial proportions in medicine. IL Charles C. Thomas, Springfield 1987.

28. Kulewicz M. Wzrost i rozwój twarzoczaszki. Acta Clinica. 2002;2:168178.

29. Gawlikowska-Sroka A. Radiological and anthropometric analysis of the symmetry and direction of evolution of skulls from some historic populations. Ann Acad Med Stetin. 2006;52:107-117.

30. McIntyre GT, Mossey PA. Asymmetry of the parental craniofacial skeleton in orofacial clefting. Journal of Orthod. 2002;29:299-305.

31. Jonas I, Mann W. Misleading X-ray diagnosis due to maxillar sinus assymetries. Laryngol Rhinol Otol. 1976;55:905-913.

32. Kim YM, Rha KS, Weissman JD, Hwang PH, Most SP. Correlation of asymmetric facial growth with deviated nasal septum. Laryngoscope. 2011;121:1144-1148.

33. Taguchi R1, Yamashita M, Kawakami S. Facial asymmetry with enlarged frontal sinus and hyperplasia of the cranial, nasal, and mandible bones. J Craniofac Surg. 2014;25:1557-1559.

34. Wysocki J, Reymond J, Skarżyński H, Wróbel B. The size of selected human skull foramina in relation to skull capacity. Folia Morphol. 2006;65:301-308.

35. Ferrario VF, Sforza C, Poggio CE, Tartaglia G. Distance from symmetry: A three-dimensional evaluation of facial asymmetry. J Oral Maxillofac Surg. 1994;52:1126-1132.

36. Farkas LG, Cheung G. Facial asymmetry in healthy North American Caucasians. Angle Orthod. 1981;51:70-77.

37. Chebib FS, Chamma AM. Indices of craniofacial asymmetry. Angle Orthod. 1981;51:214-226.

38. Woo TL. On the asymmetry of the human skull. Biometrika. 193031;22:324-351.

39. Kimura D. Right temporal lobe damage. Arch Neurol. 1963;8:264271.

40. Bryden MP, Rainey CA. Left-right differences in tachistoscopic recognition. Journal of Experimental Psychology, 1963;66:568-571.

41. Luria AR. The working brain. Basic Books, NY, 1973. 